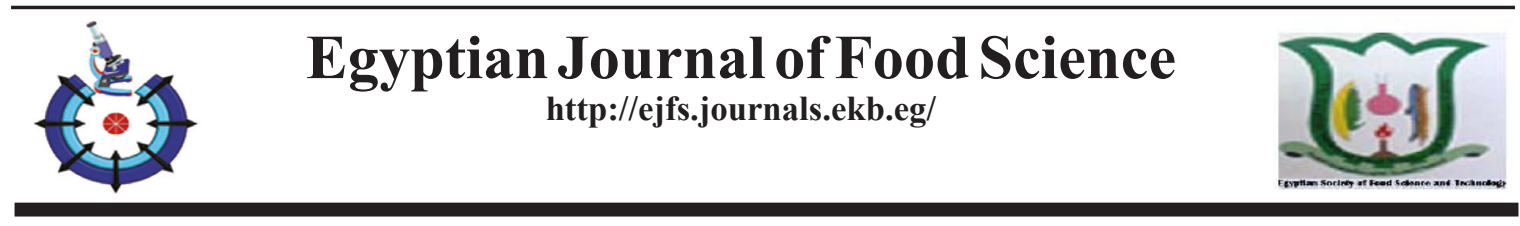

\title{
Morphological Characteristics of Fungi Species Isolated From Dairy Products in Fayoum Governorate
}

\author{
Hosam-Eddin M. El-Garhi*, Hebatullah M. Abu-Elheba, Ehab A. Galal and Neimat \\ A. H.Elewa \\ Dairy Science and Technology Department, Faculty of Agriculture, Fayoum University, \\ Fayoum, Egypt
}

\begin{abstract}
$\mathbf{E}$ IGHTY samples of different dairy products were collected from different markets in Fayoum Governorate. Samples were examined for incidence of filamentous fungi. Thirty five isolates of fungi were isolated and morphologically identified. The identification of fungi isolates mainly depended on colony characteristics (color and texture) and microscopic appearance including shape and branching of conidiophores, presence or absence of metulae, shape of phialides and texture of conidia. Filamentous fungi were isolated on Sabouraud Dextrose Agar (SDA) medium. Czapek Yeast Extract Agar (CYA) medium was used for the morphological identification of isolated fungi colonies. Lactophenol cotton blue dye was used to stain the microscopic slides of fungi species to prepare to microscopic examination. Then the microscopic images were taken by Canon G6 digital camera at a microscopic magnification power 1000x. The results revealed that all isolates fell into five fungi species classified into (four species of Aspergillus terreus, nine o fAspergillus niger, nine of Aspergillus flavus, eight of Aspergillus parasiticus, and five of Penicillium corylophilum).
\end{abstract}

Keywords: Fungi, Aspergillus, Penicillium, Morphological characterization.

\section{Introduction}

Fungi play an important role in dairy products. Since fungi mostly cause organoleptic changes, desirable in some circumstances, but they can be harmful in other instances because of the production of secondary metabolites such as mycotoxins.However, fungal contamination causes several undesirable organoleptic changes such as: gas production, off-flavors, off-odors, proteolysis, and lipolysis (Horwood et al. 1987; Vivier et al. 1994 and Maraz \& Kovacs, 2014). Moreover, growth of moulds is a defect which occurs usually on surface of hard cheese and packaged cheese (Hocking and Faedo, 1992). Most moulds commonly found belonged to Penicillium and Aspergillus and were commonly spread contaminants of cheese (Gandomi et al. 2009).

However most Aspergillus species cause economical losses through poor appearance, off flavours as well as public health hazards due to their secondary toxic metabolites. Some of these mycotoxins as Strigmat and Ocystin may cause liver cancer (Hemant et al. 2005).

Fungi, especially moulds, can be morphologically identified by determining colonial features and morphological structure (Asan A. 2004 and Mushimiyimana et al. 2016). Also, fungi are identified on the basis of gross cultural and microscopic characteristics described by Samson et al. (1998) and Pal (2007). Moreover, El-Fadaly et al. (2015) identified some fungal isolates isolated from Ras cheese in Egypt according to morphological characteristics of colonies in different cultivation media.

The objective of this research has been focused on the isolation and identification of filamentous fungi present in some dairy products collected from Fayoum governorate, Egypt.

"Corresponding author: Email, hmm03@fayoum.edu.eg

Received: 26/4/2020; accepted: 1/6/2020

DOI: 10.21608/EJFS.2020.28797.1051

(C2020 National Information and Documentation Centre (NIDOC) 


\section{Materials and Methods}

Materials

Sample collection

Eighty samples of some dairy products (hard and soft cheese, market yoghurt, buttermilk, butter, cream and mozzarella cheese) were collected from different markets in Fayoum Governorate.

\section{Microbiological media}

Sabouraud Dextrose Agar (SDA) consists of $5 \mathrm{~g}$ peptone from meat; $5 \mathrm{~g}$ peptone from casein; $40 \mathrm{~g}$ glucose; $15 \mathrm{~g}$ agar, were obtained from Merck company.

Czapek Yeast Extract Agar (CYA) consists of 30 gsucrose $5 \mathrm{~g}$ yeast extract 1 gdipotassium hydrogen phosphate 0.3 gsodium nitrate $0.05 \mathrm{~g}$ potassium chloride $0.05 \mathrm{~g}$ magnesium sulphate $0.001 \mathrm{~g}$ ferrous sulphate $0.001 \mathrm{~g}$ zinc sulphate $0.001 \mathrm{~g}$ copper sulphate15.00 agar were obtained from Merck company.

Lactophenol cotton blue stain consists of $25 \mathrm{~g}$ phenol crystals; $0.05 \mathrm{~g}$ cotton blue; $25 \mathrm{~g}$ lactic acid; $20 \mathrm{~g}$ glycerol; distilled water to final volume 100 $\mathrm{ml}$ was prepared and used for staining fungal isolates for microscopic analysis.

Chemicals were obtained from Sigma and Merck companies and all the chemicals used for this study were analytical grade (A.R.).

\section{Methods}

Isolation of fungal elements

For preparing to experiments $10 \mathrm{~g}$ of each dairy sample were aseptically withdrawn and mixed in a flask containing $90 \mathrm{ml}$ of sterilized distilled water. $10 \mathrm{ml}$ of tri-sodium citrate $(20 \% \mathrm{w} /$ vsolution) was added to $10 \mathrm{~g}$ of cheese samples before $80 \mathrm{ml}$ of sterilized distilled water was added. Plates were inoculated by $1 \mathrm{ml}$ of the previous dilution and incubated at $25^{\circ} \mathrm{C}$ for 5 days. Filamentous fungi grown in separated colonies were isolated on SDAmedium

\section{Morphological identification of Fungal isolates}

Identification basically depended on the morphological characteristics of fungal isolates grown on CYA cultivation medium. Colony characteristics (mainly color and texture) and microscopic appearance including shape and branching of conidiophores, vesicle size, presence or absence of metulae, shape of phialides, texture and dimensions of conidia were used for identification of isolated fungi in Assiut University Moubasher Mycological Centre (AUMMC), Assiut, Egypt, according to Manga et al. (2014).

\section{Microscopic examination}

Microscopic slides were prepared using scotch tape preparation method (Larone, 1995) wherein thefungi adhering to cello tape flag were mounted in lactophenol cotton blue. All fungi isolates were microscopically examined using trinocular Carl Zeiss, Axiostar Plus microscope and the micrographswere taken by Canon G6 digital camera (7.1 megapixels, with a magnificationpower $1000 x$,made in Japan). according to Raper and Fennell (1965), Pitt (1979) and Domsch et al. (2007).

\section{Results and Discussion}

Isolation and identification of fungal elements

As shown in Table 1, 35 fungal isolates were isolated and morphologically identified. Five groups of isolates were obtained (four of Aspergillus terreus Thom, nine of Aspergillus niger van Tieghem, nine of Aspergillus flavus Link, eight of Aspergillus parasiticus Speare, and five of Penicillium corylophilum Dierckx).

TABLE 1. Identified fungal species isolated from some dairy products in Fayoum Governorate.

\begin{tabular}{|c|c|c|c|}
\hline AUMMC No. & Isolates count & Isolates ratio \% & Identification \\
\hline 14054 & 4 & 11.4 & Aspergillus terreus \\
\hline 14055 & 9 & 25.7 & Aspergillus niger \\
\hline 14056 & 9 & 25.7 & Aspergillus flavus \\
\hline 14057 & 8 & 22.9 & Aspergillus parasiticus \\
\hline 14058 & 5 & 14.3 & Penicillium corylophilum \\
\hline
\end{tabular}

AUMMC: Assiut University Moubasher Mycological Centre

Egypt. J. Food Sci. 48, No.1 (2020) 
Morphological identification and microscopic examination of isolatedfungal species

As illustrated from the previous obtained results in Table 1, 35 fungal species were identified and divided into five fungal species.

\section{Aspergillus terreus}

Four isolates out of thirty-five were identified as Aspergillus terreus according to their colony characteristics (mainly color and texture) and microscopic appearance. As shown from Fig. 1, Aspergillus terreus colony has smooth-like walls, is brownish in color with off-white edges and gets darker as it ages on CYA medium Balajee (2009). Aspergillus terreus has conidial heads that are compact, biseriate, and densely columnar. Conidiophores of $A$. terreus are smooth and hyaline. The conidia of $A$. terreus are small, about $2 \mu \mathrm{m}$ in diameter, globose-shaped, smooth- walled and can vary from light yellow to hyaline (Bizukojc and Ledakowicz, 2010).

\section{Aspergillus niger}

Nine isolates out of thirty-five were identified as Aspergillus nigeraccording to their colony characteristics (mainly color and texture) and microscopic appearance. Figure 2 showed that Aspergillus niger colony is always starting white then quickly becoming black with conidial production. Hyphae are septate and hyaline. Conidial heads are splitting into columns. Conidiophores are long $(400-3000 \mu \mathrm{m})$, smooth, and hyaline, becoming darker at the apex and terminating in a globose vesicle $(30-75 \mu \mathrm{m}$ in diameter) that in agreement with Steinbach and Stevens (2003). Metulae and phialides cover the entire vesicle. Conidia are brown to black, very rough, globose.
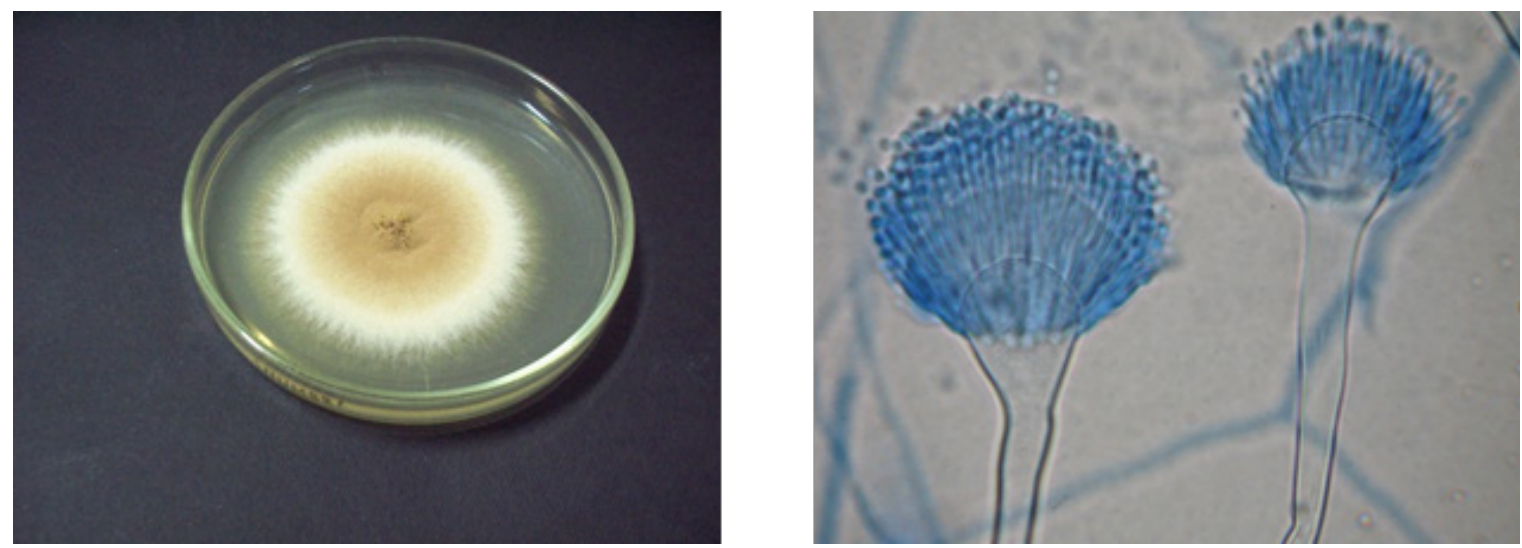

Fig. 1. Aspergillus terreus colony on CYA medium and its microscopic image.
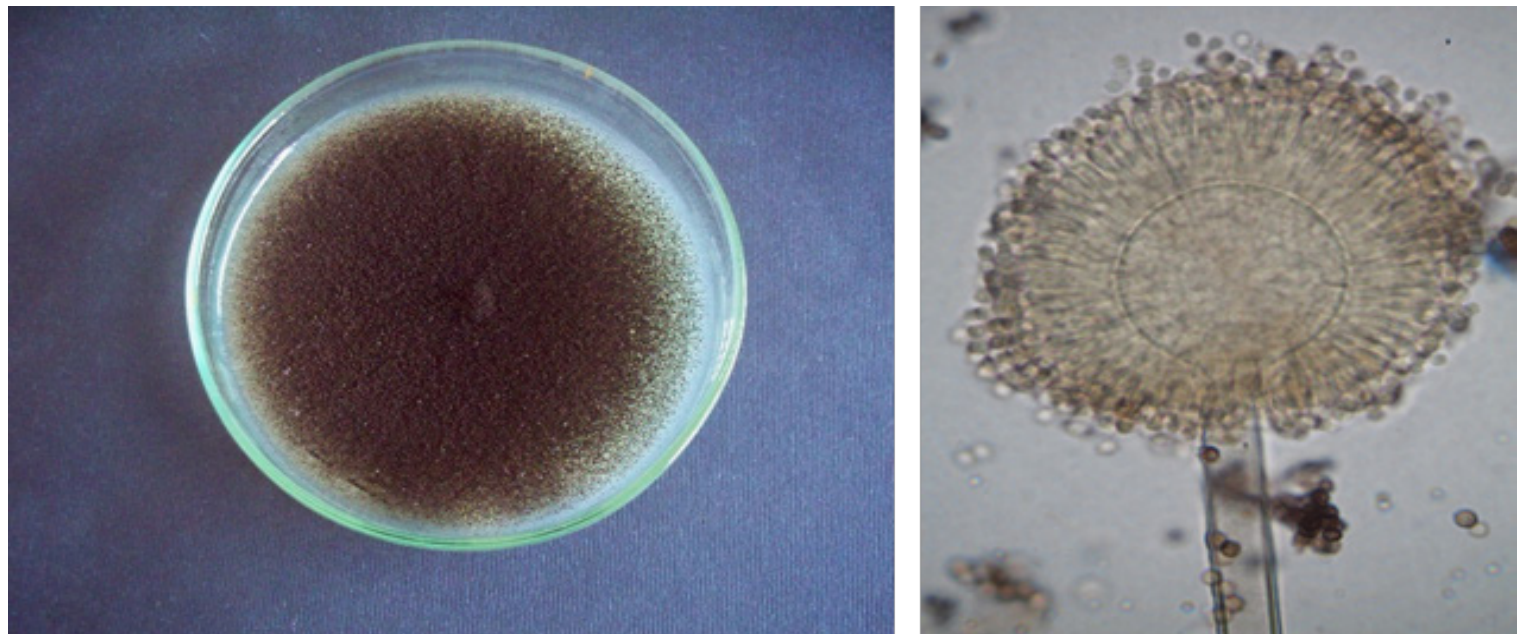

Fig. 2. Aspergillus niger colony on CYA medium and its microscopic image. 


\section{Aspergillus flavus}

Nine strains of isolated fungal cultures were found to belong to Aspergillus flavus according to their colony characteristics (mainly color and texture) and microscopic appearance. It is clear from Fig. 3 that Aspergillus flavus colony had dark green conidia except the colony edge that was greenish-yellow. Moreover, the colony appeared downy or powdery in texture.Under microscope, A. flavus appeared to have radiating conidial heads. While the conidiophores appeared thickwalled and rough. The conidia were globose with thin wall. That were proved by Thathana et al. (2017).

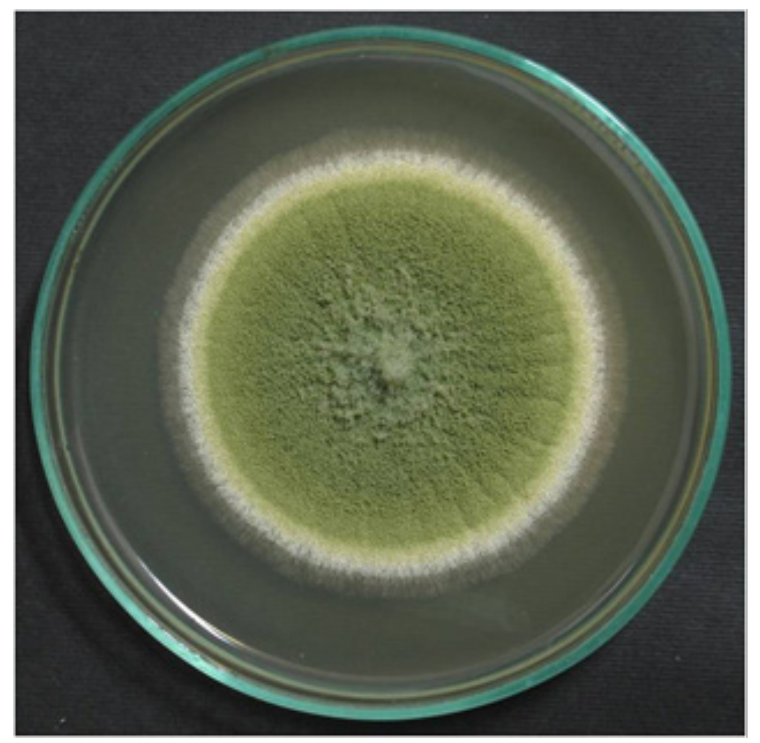

\section{Aspergillus parasiticus}

Eight isolates out of thirty-five were identified as Aspergillus parasiticus according to their colony characteristics (mainly color and texture) and microscopic appearance. Figure 4 obviously showed that Aspergillus parasiticus colony was green as a color of olive with light green edge. The conidia of $A$. parasiticus had rough, thick walls and were spherical in shape. Conidial heads of $A$. parasiticus were dark green and unbranched. Conidia were distinctly roughened, globose to subglobose and are borne on stalks, which are commonly covered in small spines as described by Horn et al. (2009)

Fig. 3. Aspergillus flavus colony on CYA medium and its microscopic image.
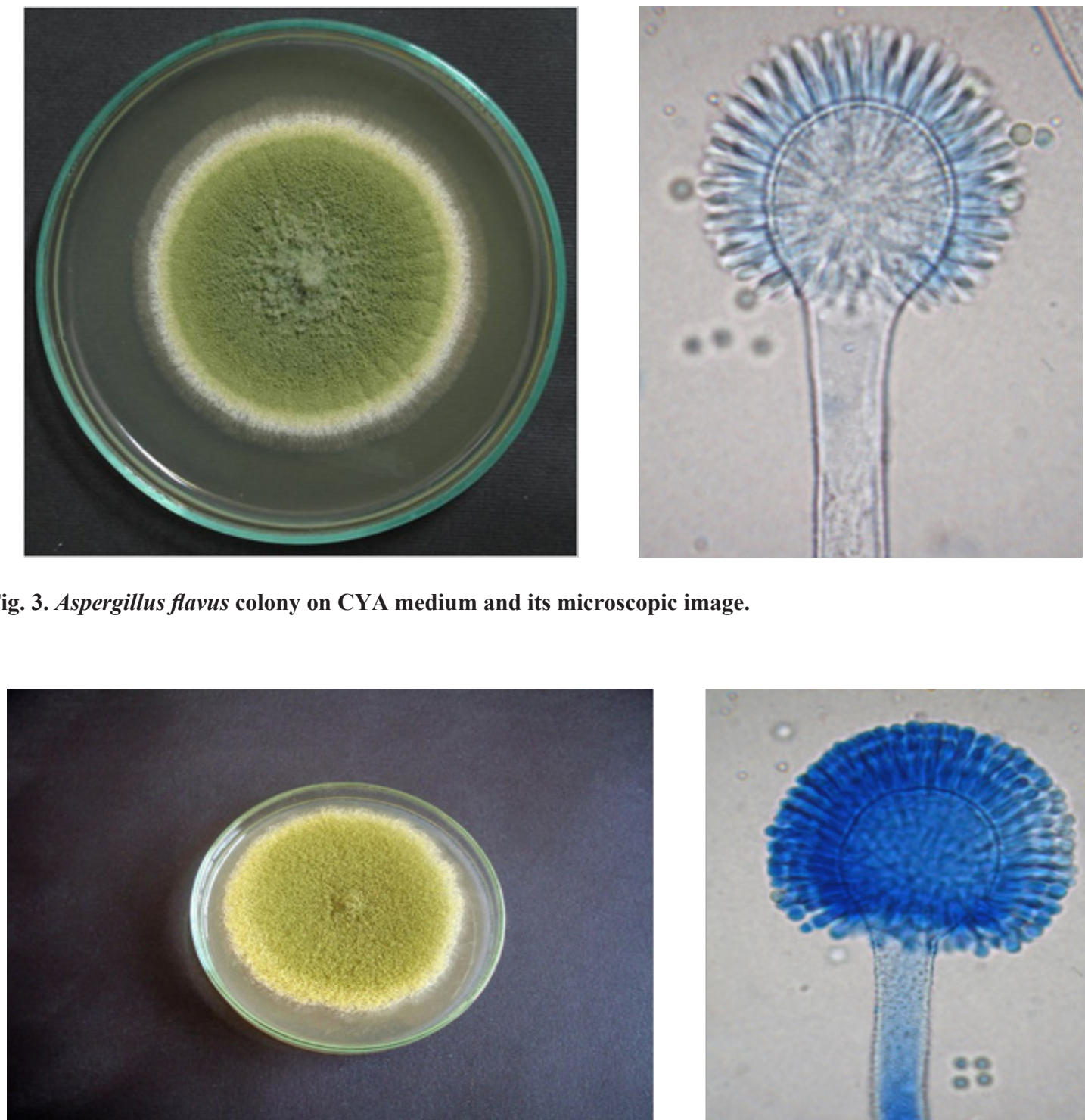

Fig. 4. Aspergillus parasiticus colony on CYA medium and its microscopic image.

Egypt. J. Food Sci. 48, No.1 (2020) 


\section{Penicillium corylophilum}

Five isolates out of thirty-five were identified as Penicillium corylophilum according to their colony characteristics (mainly color and texture) and microscopic appearance. It is obviously clear from Fig. 5 that $P$. corylophilum colony was dark green at the center of the colony, however the edges of the colony were white to greenish white. The mycelium of $P$. corylophilum had high branched networks of multinucleated cells located on a septum lacking hyphae. Conidiophores are at the end of each branch accompanied by green spherical constricted units called conidiospores as described by McMullin et al. (2014).
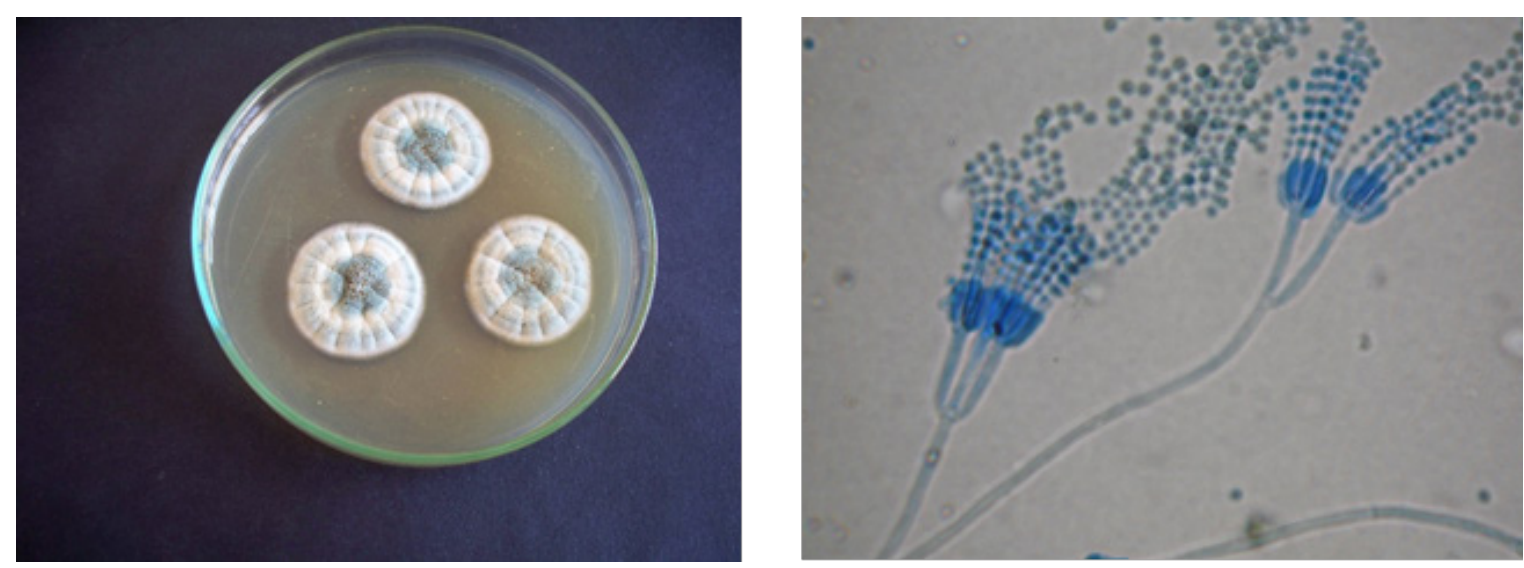

Fig. 5. Penicillium corylophilum colony on CYA medium and its microscopic image. 


\section{References}

Asan A. (2004) Aspergillus, Penicillium and related species reported from Turkey. Mycotaxon, 89: 155157.

Balajee S. A. (2009) Aspergillus terreus complex, Medical Mycology, 47 (1): 42-46.

Bizukojc M. and Ledakowicz, S. (2010) The morphological and physiological evolution of Aspergillus terreus mycelium in the submerged culture and its relation to the formation of secondary metabolites. World J Microbiol Biotechnol. 26: 4154.

Domsch K. H., Gams W. and Anderson T-H. (2007) Compendium of soil fungi. IHW-Verlag, Eching (672 pages).

El-Fadaly H. M., El-Kadi S. M., Hamad M. N. and Habib A. A. (2015) Isolation and Identification of Egyptian Ras Cheese (Romy) Contaminating Fungi during Ripening Period. Journal of Microbiology Research, 5 (1): 1-10.

Gandomi H., Misaghi A., Basti A. A., Bokaei S., Khosravi A., Abbasifar A. and Javan A. J. (2009) Effect of Zataria multiflora Boiss. essential oil on growth and aflatoxin formation by Aspergillus flavus in culture media and cheese., Food and Chemical Toxicology 47: 2397-2400.

Hemant K., Nancy P. and Thoman H. (2005) Aspergillus nidulans and O-Methyltransferase Required for Sterigmatocystin Biosynthesis. International Journal of Dairy Technology, 55 (2): 244-250

Hocking A.D., and Faedo, M. (1992) Fungi causing thread mould spoilage of vacuum packaged Cheddar cheese during maturation. Int. J. Food Microbiol. 16 (2): 123-130.

Horn B. W., Ramirez-Prado J. H. and Carbone, I. (2009) The sexual state of Aspergillus parasiticus. Mycologia. 101: 275 - 280.

Horwood J. F., Stark W.and Hull H. H. (1987) A fermented, yeasty 82 engal defect in Cheddar cheese. Australian Journal of Dairy Technology, 42: $25-26$.

Larone D. H. (1995). Medically important fungi, $3^{\text {rd }}$ ed. ASM Press, Washington, D.C.
Manga M., Bansa S. and Sharma M. (2014) Macro and micromorphological characterization of different Aspergillus isolates. Legume Res., 37 (4): 372-378

Maraz A., and Kovacs, M. (2014) Food Spoilage by Cold-Adapted Yeasts. In: Buzzini, P., Margesin, R. (Eds.), Cold- Adapted Yeasts, Springer.

McMullin D. R., Nsiama T. K., and Miller J. D. (2014) Isochromans and $\alpha$-Pyrones from Penicillium corylophilum. Journal of Natural Products, 77: 206-212

Mushimiyimana I., Kimonyo A. and Nsabimana P. (2016) Colonial and Morphological Characteristics of various fungi Species Isolated from soil in Bangalore city. Bull. Env. Pharmacol. Life Sci., 6 (1): $17-21$

Pal M. (2007) Veterinary and Medical Mycology. $1^{\text {st }}$ edition. Indian Council of Agricultural Research, New Delhi, India.

Pitt J. I. (1979) The genus Penicillium and its Teleomorphic states. Academic Press London (634 pages).

Raper K. B. and Fennell D. I.(1965) The genus Aspergillus. Williams \& Wilkins, Baltimore.

Samson R.A.,HoekstraE.S., Frivad J.C. and Smith M.T. (1998) Introduction to Foodborne Fungi. Third edition, Centralbureau Voor Schimmel cultures, Barn, Delft, Netherlands.

Steinbach W. J. and Stevens D. A. (2003) Review of newer antifungal and immunomodulatory strategies for invasive aspergillosis. Clin Infect Dis., 37:157187.

Thathana M. G., Murage H., Abia A. L. and Pillay M. (2017) Morphological Characterization and Determination of Aflatoxin-Production Potentials of Aspergillus flavus Isolated from Maize and Soil in Kenya. Agriculture 7 (80): 1-14.

Vivier D., Rivemale M., Reverbel J. P., Ratomahenina R., and Galzy P. (1994) Study of the growth of yeasts from Feta cheese. International Journal of Food Microbiology, 22: 207-215. 


\section{الخصائص المورفولوجية لبعض أنواع الفطريات المعزولة من بعض منتجات الألبان في محافظة الفيوم الكورف}

تم جتميع •^ عينة من منتجات الألبان الختلفة من الأسـواق الخختلفة في محافظة الفيوم. ولقد أختبرت

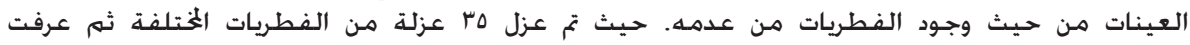

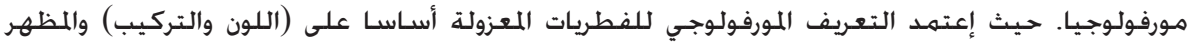

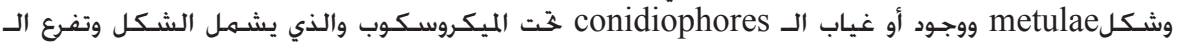

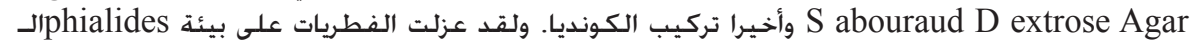

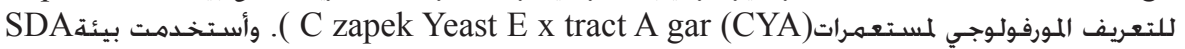
L actophenol cotton blue

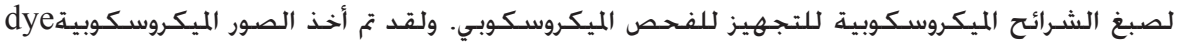

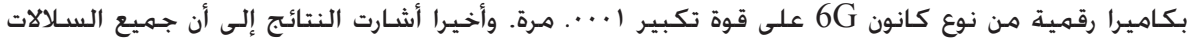

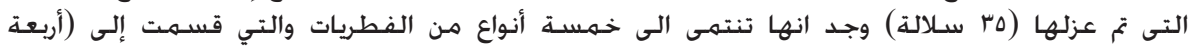
Aspergillus terreus Aspergillus

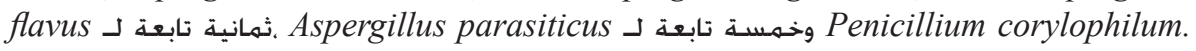

